\title{
Meridional thermospheric neutral wind at high latitude over a full solar cycle
}

\author{
O. Witasse, J. Lilensten, C. Lathuillere, B. Pibaret \\ LIS, BP 46, F-38402 St Martin d'Heres Cedex, France \\ Fax: + 3304768263 84; e-mail: Olivier.Witasse@lis.inpg.fr \\ Received: 13 November 1997 / Revised: 9 February 1998 / Accepted: 6 March 1998
}

\begin{abstract}
EISCAT radar experiments over a full solar cycle between January 1984 and March 1995 have been used to construct meridional neutral wind patterns in the ionospheric $\mathrm{F}$ region. For locally geomagnetically quiet periods the neutral winds have been binned according to season, solar activity, and universal time. The diurnal and seasonal behaviors and the effect of the solar flux are described. An empirical model of the meridional neutral wind for the high latitudes at eight altitudes in the ionospheric $\mathrm{F}$ region over a full solar cycle is presented. Results are compared with other recent empirical models.
\end{abstract}

Key words. Auroral ionosphere $\cdot$ Thermospheric dynamics $\cdot$ EISCAT

\section{Introduction}

The meridional component of the neutral wind deduced from incoherent-scatter radar (ISR) measurements has been studied for more than 20 years (Vasseur, 1969; Salah and Holt, 1974). F-region wind measurements above EISCAT have already been calculated for short periods by several authors (Winser et al., 1988; Titheridge, 1991; Lilensten et al., 1992; Lilensten and Lathuillere, 1995). At mid-latitude several studies have also been performed. For example, Oliver et al. (1990) described winds over Japan at $250 \mathrm{~km}$ height. Duboin and Lafeuille (1992) analyzed measurements of a 15year period over Saint-Santin (France) to investigate the influence of solar fluxes, magnetic activity, and season at an altitude of $300 \mathrm{~km}$. Hagan (1993) built a neutral-wind climatology over Millstone Hill (USA) by using data from a 7-year period, again at an altitude of $300 \mathrm{~km}$.

Correspondence to: $\mathrm{O}$. Witasse
Direct measurements of the neutral wind are also made by optical facilities, but such studies are limited to nighttime, and the height is assumed to be a fixed height corresponding to the emission peak (approximately 250 $\mathrm{km}$ for oxygen red-line measurements).

At high latitudes Fauliot et al. (1993) published a model for wind during high solar activity periods which included the vertical wind behavior. Recently, Aruliah et al. (1996) studied the wind over a full solar cycle, and showed it to have an equinoctial asymmetry not predicted by any numerical simulations. Hedin et al. (1991) published a model for thermospheric wind based on data from satellites and ground-based observations. This model (HWM) is mostly constructed from low- and mid-latitude data and is therefore not dependable for high-latitude studies.

The aim of this paper is to propose a model of meridional neutral thermospheric wind deduced from ISR at high latitude $(70 \mathrm{~N}, 19 \mathrm{E})$. We have used experimental data from an 11-year period and have rejected locally geomagnetic disturbed periods. The interest of this study is to classify the wind behavior as a function of two solar activity levels, four seasons, for a whole day, at eight altitudes between 185 and $354 \mathrm{~km}$.

First the EISCAT data set used in this study is presented. Then the method and the assumptions made to calculate the wind from ISR measurements are reviewed. The criteria used to reject disturbed periods are explained. After rejecting an $A_{p}$ discrimination, eight classes of wind dependent on the solar flux and the season are defined. Following this, wind patterns are built and described. We present a model including harmonic components with periods of 24,12 , and $8 \mathrm{~h}$. Comparisons are finally made with other available models.

\section{Wind computation}

\subsection{The data set}

Sixty-five ISR experiments representing 119 days between January 1984 and March 1995 have been 
analyzed. During most of these experiments the radar was operating in a fixed mode with the Tromsø antenna looking along the direction of the magnetic field (CP1like mode). In a few experiments the radar was operating a four-position scan (CP2 mode). In these cases we have selected the data corresponding to the field-aligned position. The integration time was 1 or 5 min. Data include measurements given by the singlepulse that correspond to eight different altitudes spaced either by 22 or $26 \mathrm{~km}$ which are between 180 and $364 \mathrm{~km}$ height. The dates used are listed in Table 1. Because there is a full solar cycle of data, we can study the influence of solar activity on the meridional wind.

Figure 1 shows the distributions of planetary index $A_{p}$ and solar flux $f_{10.7}$ for the collected data. $A_{p}$ ranges between 2 and 62 with a median value equal to 11 . The solar fluxes range between 69 and 273 with a median value of 120 .

\subsection{The method}

The method used to deduce the meridional component of the neutral wind is described in Lilensten and Lathuillere (1995). The meridional wind (positive northward) is given by:

$U_{\text {merid }}=\frac{1}{\cos I}\left(-V_{i \|}+V_{\text {diff }} \sin I-V_{z} \sin I\right)$,

where $I$ is the dip angle, $V_{i \|}$ the ion velocity along the magnetic field line (positive upward), $V_{\text {diff }}$ is the ambipolar diffusion velocity, and $V_{z}$ the vertical wind (positive upward).

$I$ is given by the IGRF model (IAGA working group, 1996) and $V_{i \|}$ is directly measured by the radar. $V_{\text {diff }}$ is taken from Lilensten and Lathuillere (1995). It depends on the gradients of the electron density and the ion and electron temperatures measured by the radar. Through the ambipolar diffusion coefficient, it also depends on the ion-neutral collision frequency. This $O+/ O$ collision frequency is given in Schunk and Nagy (1978). It has not been multiplied by the Burnside factor (Salah,
1993) in accordance with the conclusions of Lathuillere et al. (1997). These authors compared wind profiles above Tromsø deduced from EISCAT data and from WINDII interferometer measurements. They found a better agreement between both profiles when this factor was not included in the formulation of the collision frequency.

The neutral densities are given by the MSIS90 model (Hedin, 1991), for which the exospheric temperature is set to the measured ion temperature at $278 \mathrm{~km}$ height (Banks and Kockarts, 1973).

The vertical wind behavior as a function of season, solar flux, and all times is not well known. Its mean value stays very small (i.e., Fauliot et al., 1993), which allows most of the studies to set it to zero. However, in periods of large electric field, it can reach values of several hundred $\mathrm{m} \cdot \mathrm{s}^{-1}$ in $\mathrm{F}$ region (Rees et al., 1984). We have therefore chosen to keep only the local quiet periods by using the following criteria:

1. When the knowledge of the electric field $E$ is available (three antennas of Tromsø, Sodankyla, and Kiruna operating simultaneously), $E<20 \mathrm{mV} \cdot \mathrm{m}^{-1}$.

2. When $E$ is unknown, we rejected data if the ion temperature at $278 \mathrm{~km}$ height was larger than the exospheric temperature given by the MSIS model plus $200 \mathrm{~K}$, as an indicator of Joule heating.

The total amount of rejected data is around $25 \%$. Figure 2 shows the 25000 data points used at a given altitude (here the closest to $250 \mathrm{~km}$ ) plotted as a function of UT. The mean wind clearly appears equatorward.

\subsection{Determination of the eight classes of wind}

Previous studies split the meridional winds according to two geophysical parameters $A_{p}$ and $f_{10.7}$, (e.g., Duboin and Lafeuille, 1992; Aruliah et al., 1996), where $f_{10.7}$ represents the solar activity and $A_{p}$ represents the geomagnetic activity. Figure 3 shows mean winds at $257 \mathrm{~km}$ height for high solar fluxes and two geomagnetic activities $\left(A_{p}<11\right.$ and $\left.A_{p}>11\right)$. There is no significant
Table 1. Dates of experiments over a full solar cycle

\begin{tabular}{|c|c|c|c|c|c|}
\hline 1984 & 1985 & 1986 & 1987 & 1988 & 1989 \\
\hline $\begin{array}{l}31 \text { Jan-1 Feb } \\
\text { 14-15 Feb } \\
\text { 6-7 Jun } \\
\text { 12-13 Jul } \\
26-27 \text { Nov } \\
12-13 \text { Dec }\end{array}$ & $\begin{array}{l}\text { 16-17 Apr } \\
\text { 14-15 May } \\
\text { 21-22 May } \\
\text { 25-26 Jun } \\
\text { 6-7 Aug }\end{array}$ & $\begin{array}{l}10-11 \text { Sep } \\
10-11 \text { Dec }\end{array}$ & $\begin{array}{l}\text { 24-25 Feb } \\
\text { 24-25 Mar } \\
\text { 12-13 May } \\
\text { 16-17 Jun } \\
\text { 28-29 Jul } \\
22-23 \text { Sep } \\
\text { 10-12 Nov } \\
\text { 17-19 Nov }\end{array}$ & $\begin{array}{l}\text { 16-20 Mar } \\
\text { 5-7 Apr } \\
\text { 3-4 May } \\
\text { 26-27 Jul } \\
\text { 30-31 Aug } \\
\text { 1 Sep } \\
\text { 6-7 Sep } \\
\text { 20-21 Sep }\end{array}$ & $\begin{array}{c}\text { 10-11 Jan } \\
\text { 4-5 Feb } \\
\text { 28-29 Mar } \\
\text { 2-3 May } \\
\text { 1-3 Aug } \\
\text { 5-6 Sep } \\
\text { 14-16 Nov }\end{array}$ \\
\hline 1990 & 1991 & 1992 & 1993 & 1994 & 1995 \\
\hline $\begin{array}{l}30-31 \text { Jan } \\
12-16 \text { Feb } \\
5-6 \text { Jun } \\
25-27 \text { Sep } \\
10-11 \text { Oct } \\
20-21 \text { Dec }\end{array}$ & $\begin{array}{l}9-10 \text { Jan } \\
20-21 \text { Feb }\end{array}$ & $\begin{array}{l}\text { 30-31 Mar } \\
1-3 \mathrm{Apr} \\
5 \mathrm{Aug} \\
27-28 \text { Oct }\end{array}$ & $\begin{array}{l}\text { 16-17 Feb } \\
20-21 \mathrm{Apr} \\
20 \mathrm{Jul}\end{array}$ & $\begin{array}{l}\text { 1-2 Mar } \\
\text { 15-16 Mar } \\
\text { 12-13 Apr } \\
\text { 8-9 Jun }\end{array}$ & $24 \mathrm{Mar}$ \\
\hline
\end{tabular}



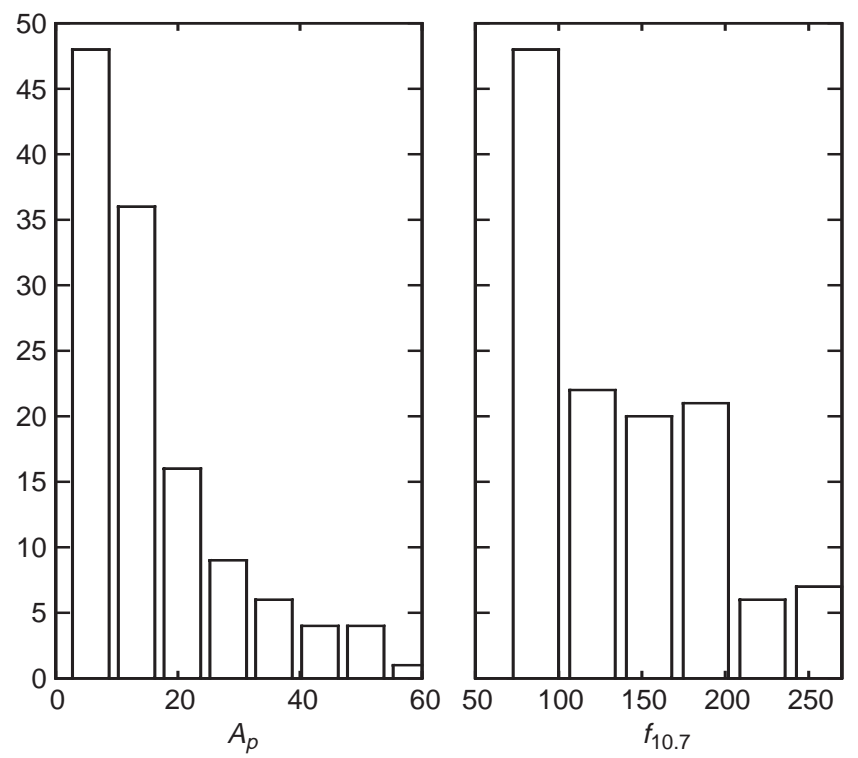

Fig. 1. Distribution of $A_{p}$ and $f_{10.7}$

difference between both levels. Mean winds respectively reach the values of $-60 \pm 6$ and $-64 \pm 8 \mathrm{~m} \cdot \mathrm{s}^{-1}$. Morning reversal times are very similar: $9 \pm 1$ and $8 \pm$ 1 UT, respectively. Midnight winds are for both cases equal to $-157 \mathrm{~m} \cdot \mathrm{s}^{-1}$. This behavior has been checked for low solar activity level. Therefore we no longer consider $A_{\mathrm{p}}$ as a pertinent criterion. This is in keeping with our choice to reject data corresponding with local magnetic active periods.

We now consider the two following parameters: season and solar flux. The sample is divided into two solar activity levels, active and quiet with the median value $f_{10.7}=120$. The seasons have been defined in the following way: winter corresponds to the period centered around December solstice \pm 45 days, spring to March equinox \pm 45 days, summer to June solstice \pm 45 days and autumn to September equinox \pm 45 days.
Eight classes of winds are then defined (Table 2) containing at least six different days. The choice of these classes often differs between several studies. For example, Duboin and Lafeuille (1992) consider two solar activity levels with a separate value of $f_{10.7}=100$. Hagan (1993) chose solar maximum periods associated with $f_{10.7}>180$ and solar minimum with $f_{10.7}<90$. Her seasons only contain 2 months.

\section{Results}

\subsection{Daily variations at $257 \mathrm{~km}$ height}

For each class of wind previously mentioned, a mean wind is calculated by storing and averaging data in 24 intervals of $1 \mathrm{~h}$. Points beyond two standard deviations $\sigma$ from the mean are discarded. No weight has been affected at each data point because such a weight is usually defined as the inverse of the measurement uncertainty squared. This uncertainty is not only a stochastic noise; it is relative to the geophysical signalto-noise ratio. Therefore a weighted mean automatically gives a greater importance to specific geophysical conditions, like high solar activity periods.

We now describe the mean wind around $257 \mathrm{~km}$ height (256 or $259 \mathrm{~km}$ depending on the year of the experiment). This altitude is chosen because it approximately corresponds to the altitude of the maximum emission intensity of the $O\left({ }^{1} D\right)$ oxygen line from which neutral winds are measured in the $F$ region with optical experiments. Figure 4 shows these wind patterns. The main wind characteristics seen in previous studies (e.g., Titheridge, 1991; Lilensten and Lathuillere, 1995) are found: winds are poleward during the daytime (50-80 $\mathrm{m} \cdot \mathrm{s}^{-1}$ ) and more strongly equatorward during the nighttime $\left(150-200 \mathrm{~m} \cdot \mathrm{s}^{-1}\right)$. The standard deviation $\sigma$ (see Table 9 in the next subsection) ranges between 34 and $66 \mathrm{~m} \cdot \mathrm{s}^{-1}$ and allows us to give the mean wind with an accuracy $\left(\frac{\sigma}{\sqrt{N}}\right)$ ranging between 2 and $12 \mathrm{~m} \cdot \mathrm{s}^{-1}$.

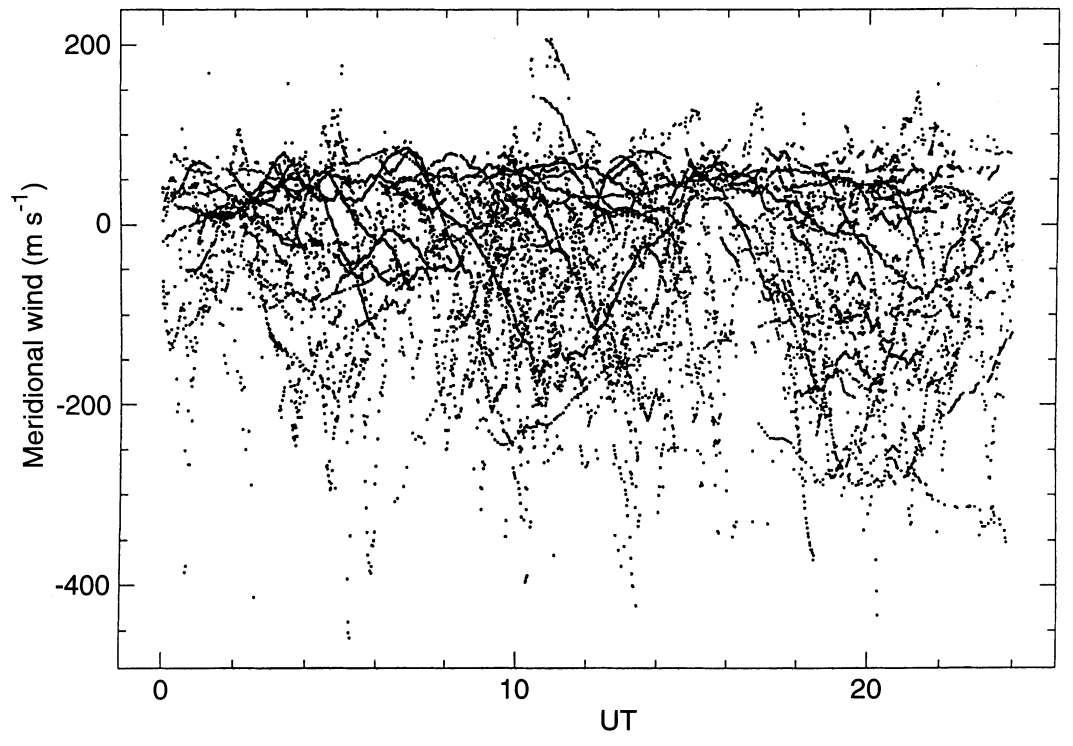

Fig. 2. Quiet-time wind data base around $250 \mathrm{~km}$ height 


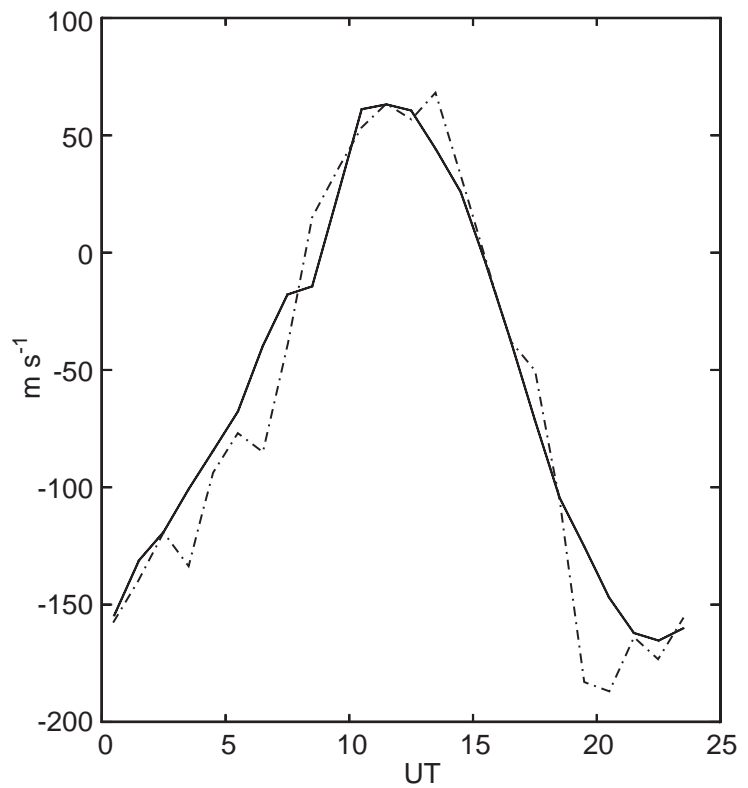

Fig. 3. Comparison between mean wind at $257 \mathrm{~km}$ height during high solar activity for two levels of magnetic activity: $A_{p}<11$ in solid line and $A_{p}>11$ in dash-dotted line

The winds averaged over $24 \mathrm{~h}$ are given in Table 3; they are always negative. The mean wind can reach $78 \mathrm{~m} \cdot \mathrm{s}^{-1}$ in summer. It is always larger during low solar activity periods. The largest difference occurs in summer: -34 to $-78 \mathrm{~m} \cdot \mathrm{s}^{-1}$.

Table 4 shows the nighttime maximum equatorward values for the eight classes. For all seasons except
Table 2. Number of days affected at each class

\begin{tabular}{lllcc}
\hline & winter & spring & summer & autumn \\
\hline$f_{10.7}>120$ & 11 & 18 & 8 & 16 \\
$f_{10.7}<120$ & 14 & 27 & 19 & 6 \\
\hline
\end{tabular}

summer, this value decreases with solar activity. The strongest variation occurs in spring $\left(-78 \mathrm{~m} \cdot \mathrm{s}^{-1}\right)$, the smallest in autumn $\left(-18 \mathrm{~m} \cdot \mathrm{s}^{-1}\right)$. In summer the maximum wind is larger for low solar activity periods. Both equinoxes differ here. The spring winds are larger than the autumn ones, especially during solar active periods. This is in agreement with the results of Aruliah et al. (1996). These maximum values are always reached before 0 UT. Furthermore, they are reached 1 to $3 \mathrm{~h}$ earlier in periods of low solar activity level.

Another interesting feature is the time when the wind direction changes. These times, in LT, in the morning and in the afternoon, are reported in Table 5. At Tromsø, $\mathrm{LT}=\mathrm{UT}+1.3$. In the afternoon there are no large differences between the classes. The velocity is equal to zero between 16 and $18 \mathrm{LT}$. In the morning the inversion time strongly depends on the solar activity: it decreases when the solar flux increases. We will show in Sect. 3.2 that this appears to be related to the semidiurnal component. The strongest change in inversion time with the solar activity occurs in summer.

Simple and general considerations of physics could explain these behaviors. The thermospheric wind is driven by pressure gradients generated by the solar radiations (mostly in the equatorial regions during the daytime) and auroral heating. For this reason, it is

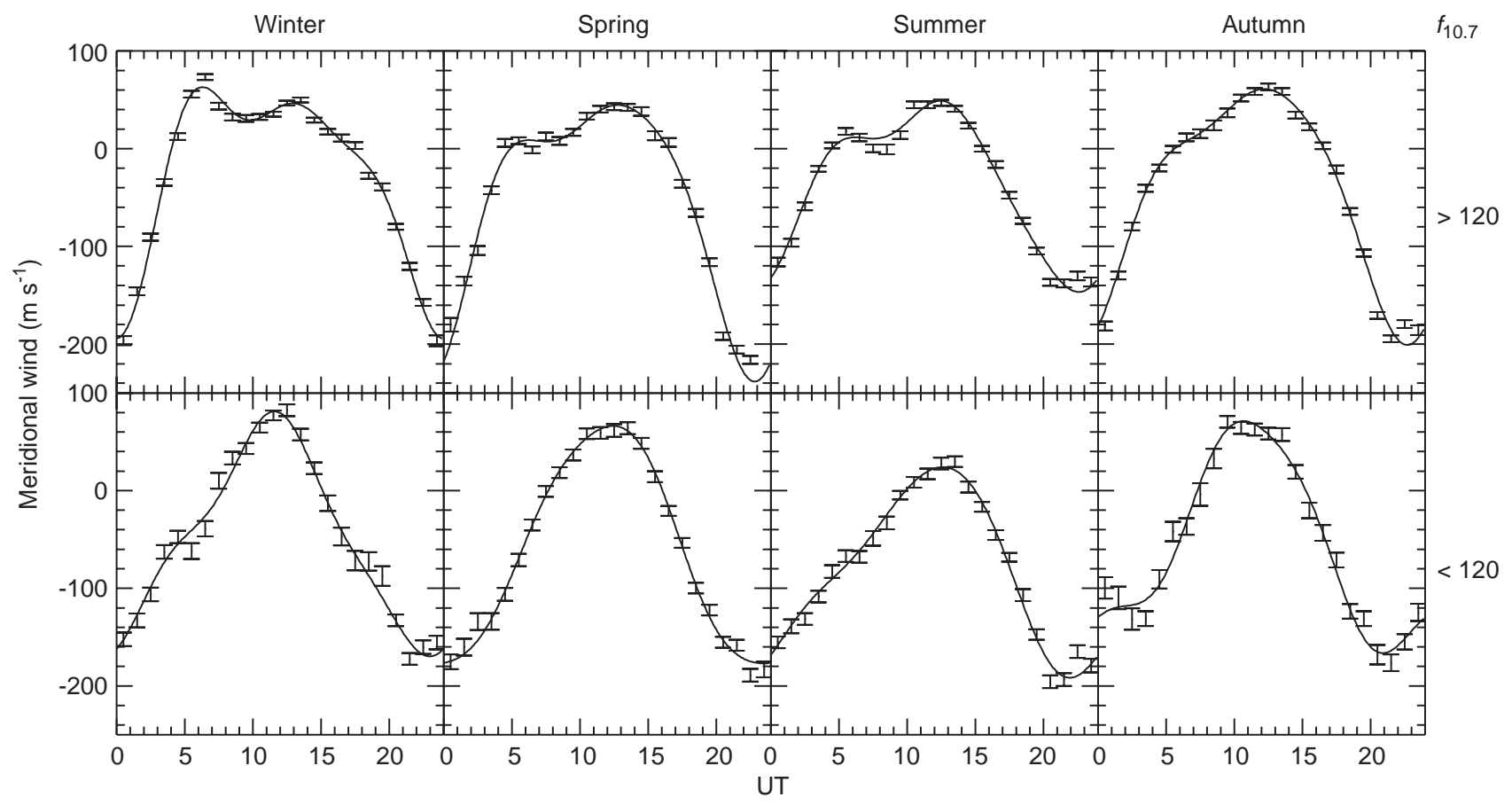

Fig. 4. Mean wind patterns (points with errorbars) and the harmonic fit (solid line) at $257 \mathrm{~km}$ height. Different classes are represented as in Table 2. The first line of boxes corresponds to high solar fluxes, the second to low solar fluxes. From left to right one can see winter, spring, summer, and autumn 
Table 3. Mean winds at $257 \mathrm{~km}$ height in $\mathrm{m} \cdot \mathrm{s}^{-1}$

\begin{tabular}{lllll}
\hline & winter & spring & summer & autumn \\
\hline$f_{10.7}>120$ & $-25 \pm 3$ & $-54 \pm 4$ & $-34 \pm 4$ & $-41 \pm 4$ \\
$f_{10.7}<120$ & $-47 \pm 7$ & $-60 \pm 6$ & $-78 \pm 6$ & $-54 \pm 8$ \\
\hline
\end{tabular}

Table 4. Nighttime maximum equatorward values in $\mathrm{m} \cdot \mathrm{s}^{-1}$

\begin{tabular}{lllll}
\hline & winter & spring & summer & autumn \\
\hline$f_{10.7}>120$ & $-196 \pm 5$ & $-267 \pm 7$ & $-137 \pm 5$ & $-194 \pm 5$ \\
$f_{10.7}<120$ & $-172 \pm 7$ & $-189 \pm 8$ & $-196 \pm 7$ & $-176 \pm 11$ \\
\hline
\end{tabular}

Table 5. Inversion time (in LT) in the morning and in the afternoon

\begin{tabular}{lllrl}
\hline & winter & spring & \multicolumn{1}{c}{ summer } & autumn \\
\hline$f_{10.7}>120$ & $5.0-17.3$ & $6.3-18.3$ & $5.8-16.3$ & $6.8-18.3$ \\
$f_{10.7}<120$ & $9.3-16.3$ & $9.0-17.3$ & $11.3-16.3$ & $8.8-16.3$ \\
\hline
\end{tabular}

equatorward by night and poleward by day. With the decrease in solar activity it is reasonable to think that the wind will be less poleward as a result of smaller pressure gradients. This is in agreement with the results of Table 3. This also explains the dependence of the inversion time with the solar activity. Effectively, timeintervals when the wind is poleward are larger in the $f_{10.7}$ $>120$ cases, particularly in summer (Table 5). On the other hand a decrease in solar activity also means a statiscal decrease in auroral heating (Lilensten et al., 1996) that can explain the correlation between the nighttime maximum equatorward wind values and the solar activity (Table 4), except in summer.

\subsection{The model}

A harmonic decomposition has been performed using the unbinned raw data. We used a subroutine for nonlinear least-squares fitting based on the GaussNewton method. Unlike other studies (e.g., Buonsanto, 1991; Hagan, 1993), we do not fit the coefficients of this decomposition on the mean daily variation. In fact, using the sample or the hourly binned winds does not give the same results because least-squares fitting is not a linear operation. However, we have checked that both methods give close results. For the summer and $f_{10.7}>$ 120 case, the mean winds are the same, diurnal and semidiurnal amplitudes differ by $2 \%$, and terdiurnal amplitudes by $19 \%$. For the same reason as explained in the previous subsection, we affected at each point the same uncertainty, here $10 \mathrm{~m} \cdot \mathrm{s}^{-1}$.

The wind velocity is described by the following equation, including diurnal, semidiurnal and terdiurnal components:

$$
\begin{aligned}
w(t)=\langle w\rangle & +A_{24} \sin \left(\omega_{24}\left(t-\phi_{24}\right)\right)+A_{12} \sin \left(\omega_{12}\left(t-\phi_{12}\right)\right) \\
& +A_{8} \sin \left(\omega_{8}\left(t-\phi_{8}\right)\right),
\end{aligned}
$$

where $\omega_{n}=\frac{2 \pi}{n}$.

Figure 4 shows the mean wind and the harmonic fit at $257 \mathrm{~km}$ height. In general, the agreement between the model and the data is excellent.

Results for all altitudes are listed in Tables 6 to 13 . They include the standard deviation $\sigma$. Its typical value increases with the altitude; for altitudes between 185 and $257 \mathrm{~km}$ this value is equal to $45 \mathrm{~m} \cdot \mathrm{s}^{-1}$, to 50 at $282 \mathrm{~km}$, to 55 at $306 \mathrm{~km}$, to 60 at $330 \mathrm{~km}$ and to $75 \mathrm{~m} \cdot \mathrm{s}^{-1}$ at $354 \mathrm{~km}$.

Figures 5 and 6 show the height amplitude and phase variation profiles. The general trend of the mean wind is an increase in the amplitude with the altitude up to 306 $\mathrm{km}$ height: typically from -25 at $185 \mathrm{~km}$ height to $-65 \mathrm{~m} \cdot \mathrm{s}^{-1}$ at $306 \mathrm{~km}$ height. It reaches a constant value above this altitude. As seen in the previous subsection the mean wind is always larger in the $f_{10.7}<120$ cases. The diurnal component shows an amplified behavior compared with the mean wind: for low solar fluxes it increases with the altitude up to $306 \mathrm{~km}\left(165 \mathrm{~m} \cdot \mathrm{s}^{-1}\right.$ in spring for example) and then decreases $\left(134 \mathrm{~m} \cdot \mathrm{s}^{-1}\right.$ at $354 \mathrm{~km}$ height in spring). This feature has already been seen in a neutral-wind mid-latitude TIGCM simulation (Hedin et al., 1994). For high solar fluxes this maximum is not reached at our maximum altitudes of measurement. The semi- and terdiurnal components are much smaller than the diurnal one and less variable: from 30 to $40 \mathrm{~m} \cdot \mathrm{s}^{-1}$ and 10 to $15 \mathrm{~m} \cdot \mathrm{s}^{-1}$, respectively.

Table 6. Harmonic decomposition at $185 \mathrm{~km}$ height. Amplitudes, mean wind, and the standard deviation are in $\mathrm{m} \cdot \mathrm{s}^{-1}$, phases in hours (likewise for Tables 7-13)

\begin{tabular}{rlrlllllll}
\hline$f_{10.7}$ & season & $\langle w\rangle$ & $A_{24}$ & $\phi_{24}$ & $A_{12}$ & $\phi_{12}$ & \multicolumn{1}{c}{$A_{8}$} & $\phi_{8}$ & $\sigma$ \\
\hline$>120$ & winter & 7 & 75 & 4.70 & 31 & 4.05 & 27 & 4.04 & 32 \\
& spring & -25 & 78 & 4.08 & 47 & 1.56 & 16 & 1.93 & 70 \\
& summer & -21 & 50 & 2.30 & 29 & -0.53 & 7 & 4.48 & 40 \\
& autumn & -19 & 79 & 4.36 & 25 & 1.24 & 6 & 0.63 & 44 \\
$<120$ & winter & -12 & 62 & 5.66 & 2 & -2.86 & 4 & 2.20 & 36 \\
& spring & -31 & 68 & 5.01 & 15 & -0.66 & 0 & 0 & 46 \\
& summer & -52 & 49 & 4.28 & 37 & 0.84 & 8 & 0.74 & 50 \\
& autumn & -40 & 66 & 4.55 & 20 & -1.52 & 11 & -2.26 & 32 \\
\hline
\end{tabular}

Table 7. Harmonic decomposition at $209 \mathrm{~km}$ height

\begin{tabular}{llrrrrrrrr}
\hline$f_{10.7}$ & season & $\langle w\rangle$ & $A_{24}$ & $\phi_{24}$ & \multicolumn{1}{c}{$A_{12}$} & $\phi_{12}$ & \multicolumn{1}{c}{$A_{8}$} & $\phi_{8}$ & $\sigma$ \\
\hline$>120$ & winter & -5 & 77 & 4.85 & 41 & 3.09 & 34 & 3.25 & 36 \\
& spring & -33 & 102 & 4.53 & 52 & 1.43 & 16 & 1.66 & 71 \\
& summer & -25 & 68 & 3.74 & 24 & 0.02 & 9 & 3.10 & 38 \\
& autumn & -24 & 97 & 4.84 & 30 & 1.54 & 7 & 1.75 & 45 \\
$<120$ & winter & -24 & 82 & 5.16 & 9 & -1.97 & 7 & 1.89 & 34 \\
& spring & -36 & 89 & 5.38 & 11 & -0.58 & 1 & -5.27 & 46 \\
& summer & -57 & 69 & 4.86 & 33 & 0.23 & 9 & 0.46 & 48 \\
& autumn & -40 & 82 & 5.09 & 20 & -2.88 & 9 & -2.14 & 35 \\
\hline
\end{tabular}


Table 8. Harmonic decomposition at $233 \mathrm{~km}$ height

\begin{tabular}{lllrllllll}
\hline$f_{10.7}$ & season & $\langle w\rangle$ & $A_{24}$ & $\phi_{24}$ & $A_{12}$ & $\phi_{12}$ & \multicolumn{1}{c}{$A_{8}$} & $\phi_{8}$ & $\sigma$ \\
\hline$>120$ & winter & -16 & 94 & 4.96 & 49 & 2.94 & 29 & 2.88 & 34 \\
& spring & -41 & 112 & 4.76 & 51 & 1.46 & 17 & 1.59 & 69 \\
& summer & -28 & 82 & 4.23 & 24 & 0.58 & 10 & 2.66 & 38 \\
& autumn & -33 & 111 & 4.90 & 33 & 1.23 & 8 & 1.58 & 44 \\
$<120$ & winter & -34 & 97 & 4.94 & 8 & -1.46 & 10 & 1.77 & 33 \\
& spring & -46 & 106 & 5.61 & 8 & -1.35 & 4 & -2.86 & 47 \\
& summer & -65 & 83 & 5.12 & 25 & -0.24 & 6 & -0.20 & 48 \\
& autumn & -44 & 93 & 4.93 & 26 & -2.76 & 13 & -1.66 & 35 \\
\hline
\end{tabular}

Table 9. Harmonic decomposition at $257 \mathrm{~km}$ height

\begin{tabular}{rlrrrrrrrr}
\hline$f_{10.7}$ & season & $\langle w\rangle$ & $A_{24}$ & $\phi_{24}$ & $A_{12}$ & $\phi_{12}$ & \multicolumn{1}{c}{$A_{8}$} & $\phi_{8}$ & $\sigma$ \\
\hline$>120$ & winter & -25 & 102 & 5.06 & 51 & 2.72 & 23 & 2.69 & 34 \\
& spring & -54 & 123 & 4.89 & 50 & 1.41 & 14 & 1.42 & 66 \\
& summer & -34 & 88 & 4.41 & 25 & 0.64 & 10 & 2.24 & 40 \\
& autumn & -41 & 118 & 4.97 & 34 & 1.17 & 10 & 1.15 & 42 \\
$<120$ & winter & -48 & 111 & 5.08 & 10 & -1.45 & 14 & 1.50 & 38 \\
& spring & -60 & 126 & 5.73 & 7 & -1.40 & 6 & -2.82 & 54 \\
& summer & -78 & 99 & 5.33 & 23 & -0.43 & 4 & -0.62 & 49 \\
& autumn & -55 & 113 & 4.97 & 22 & -2.90 & 13 & -1.58 & 40 \\
\hline
\end{tabular}

Table 10. Harmonic decomposition at $282 \mathrm{~km}$ height

\begin{tabular}{llllllllll}
\hline$f_{10.7}$ & season & $\langle w\rangle$ & $A_{24}$ & $\phi_{24}$ & \multicolumn{1}{c}{$A_{12}$} & $\phi_{12}$ & \multicolumn{1}{c}{$A_{8}$} & $\phi_{8}$ & $\sigma$ \\
\hline$>120$ & winter & -37 & 10.7 & 5.10 & 51 & 2.56 & 21 & 2.59 & 35 \\
& spring & -68 & 133 & 5.08 & 53 & 1.38 & 12 & 1.24 & 65 \\
& summer & -43 & 93 & 4.52 & 27 & 0.72 & 12 & 1.98 & 44 \\
& autumn & -51 & 126 & 5.09 & 35 & 1.22 & 9 & 0.99 & 44 \\
$<120$ & winter & -60 & 127 & 5.30 & 11 & -1.58 & 20 & 1.33 & 45 \\
& spring & -72 & 149 & 5.95 & 4 & 0.72 & 5 & -2.54 & 61 \\
& summer & -89 & 115 & 5.57 & 22 & -0.34 & 5 & -2.15 & 54 \\
& autumn & -61 & 129 & 5.12 & 16 & -3.73 & 14 & -1.73 & 47 \\
\hline
\end{tabular}

The semidiurnal components show solar activity variation: it increases with the solar activity and appears very weak in the $f_{10.7}<120$ cases, except in winter. At $257 \mathrm{~km}$ height $A_{12}$ ranges between 25 and $51 \mathrm{~m} \cdot \mathrm{s}^{-1}$ at solar maximum and between 7 and $23 \mathrm{~m} \cdot \mathrm{s}^{-1}$ at solar minimum. The terdiurnal component does not appear significant.

The three phases (Fig. 6) are generally constant with altitude. Two groups appear: on the one hand the diurnal phase around 5-6 h and on the other hand the semi- and the terdiurnal phases which are close to each other. The most interesting feature is that generally the semidiurnal phase is positive during high solar activity periods and negative during low solar activity periods, except in spring and the $f_{10.7}<120$ case above $282 \mathrm{~km}$ height. This can explain the dependence of the reversal time on the solar flux. The terdiurnal phase behavior is not really significant because of the weakness of the amplitude of this component.
Table 11. Harmonic decomposition at $306 \mathrm{~km}$ height

\begin{tabular}{rlrrrrrrrr}
\hline$f_{10.7}$ & season & $\langle w\rangle$ & $A_{24}$ & $\phi_{24}$ & \multicolumn{1}{c}{$A_{12}$} & $\phi_{12}$ & \multicolumn{1}{c}{$A_{8}$} & $\phi_{8}$ & $\sigma$ \\
\hline$>120$ & winter & -48 & 118 & 5.18 & 52 & 2.44 & 19 & 2.49 & 35 \\
& spring & -82 & 147 & 5.27 & 60 & 1.40 & 13 & 1.09 & 67 \\
& summer & -52 & 96 & 4.65 & 29 & 0.74 & 12 & 1.73 & 48 \\
& autumn & -60 & 137 & 5.25 & 42 & 1.28 & 13 & 0.80 & 51 \\
$<120$ & winter & -58 & 146 & 5.50 & 11 & -2.02 & 29 & 1.07 & 53 \\
& spring & -77 & 168 & 6.23 & 15 & 2.54 & 7 & -0.48 & 70 \\
& summer & -85 & 120 & 5.69 & 22 & -0.29 & 6 & -2.49 & 63 \\
& autumn & -62 & 130 & 5.44 & 9 & -4.49 & 19 & -1.47 & 62 \\
\hline
\end{tabular}

Table 12. Harmonic decomposition at $330 \mathrm{~km}$ height

\begin{tabular}{llllllllll}
\hline$f_{10.7}$ & season & $\langle w\rangle$ & $A_{24}$ & $\phi_{24}$ & $A_{12}$ & $\phi_{12}$ & $A_{8}$ & $\phi_{8}$ & $\sigma$ \\
\hline$>120$ & winter & -55 & 128 & 5.25 & 51 & 2.25 & 17 & 2.55 & 37 \\
& spring & -90 & 157 & 5.47 & 66 & 1.46 & 15 & 0.97 & 70 \\
& summer & -57 & 100 & 4.73 & 28 & 0.87 & 10 & 1.51 & 50 \\
& autumn & -66 & 146 & 5.36 & 46 & 1.17 & 15 & 0.78 & 60 \\
$<120$ & winter & -49 & 139 & 5.21 & 18 & -1.29 & 20 & 0.74 & 54 \\
& spring & -75 & 160 & 6.50 & 20 & 2.82 & 15 & -0.31 & 80 \\
& summer & -77 & 101 & 5.16 & 22 & -0.64 & 5 & -2.50 & 66 \\
& autumn & -78 & 100 & 6.03 & 19 & -3.60 & 20 & -1.39 & 86 \\
\hline
\end{tabular}

Table 13. Harmonic decomposition at $354 \mathrm{~km}$ height

\begin{tabular}{llllllllll}
\hline$f_{10.7}$ & season & $\langle w\rangle$ & $A_{24}$ & $\phi_{24}$ & $A_{12}$ & $\phi_{12}$ & \multicolumn{1}{c}{$A_{8}$} & $\phi_{8}$ & \multicolumn{1}{c}{$\sigma$} \\
\hline$>120$ & winter & -57 & 136 & 5.21 & 49 & 1.93 & 14 & 2.48 & 39 \\
& spring & -92 & 160 & 5.52 & 70 & 1.33 & 15 & 0.79 & 74 \\
& summer & -56 & 102 & 4.75 & 27 & 0.78 & 9 & 1.47 & 48 \\
& autumn & -69 & 149 & 5.42 & 51 & 0.97 & 13 & 0.72 & 68 \\
$<120$ & winter & -55 & 99 & 4.01 & 24 & -0.74 & 8 & -2.75 & 81 \\
& spring & -73 & 134 & 6.40 & 15 & 1.46 & 21 & -0.20 & 115 \\
& summer & -73 & 76 & 3.41 & 36 & -1.53 & 14 & -2.27 & 72 \\
& autumn & -119 & 53 & 5.01 & 65 & -3.09 & 26 & -1.96 & 95 \\
\hline
\end{tabular}

\section{Discussion}

Fauliot et al. (1993) (FTH) presented a model of the Fregion horizontal wind at high latitude from the MICADO interferometer measurements during three winter campaigns from 1988 to 1991. This model gives meridional wind in winter for three magnetic activities and high solar fluxes at a typical height of $250 \mathrm{~km}$ for typical times between 14 and 5 UT. Comparisons on Fig. 7 are then made between the FTH model (here corresponding to the medium magnetic activity) and our winter and high solar flux data. Relatively good agreement has been found for time-intervals between 16 and 5 UT, especially the morning and afternoon reversal times. Some discrepancies appear between 14 and 16 UT where the FTH model overestimates the wind velocity. At midnight the FTH model underestimates the wind velocity by around $40 \mathrm{~m} \cdot \mathrm{s}^{-1}$. 


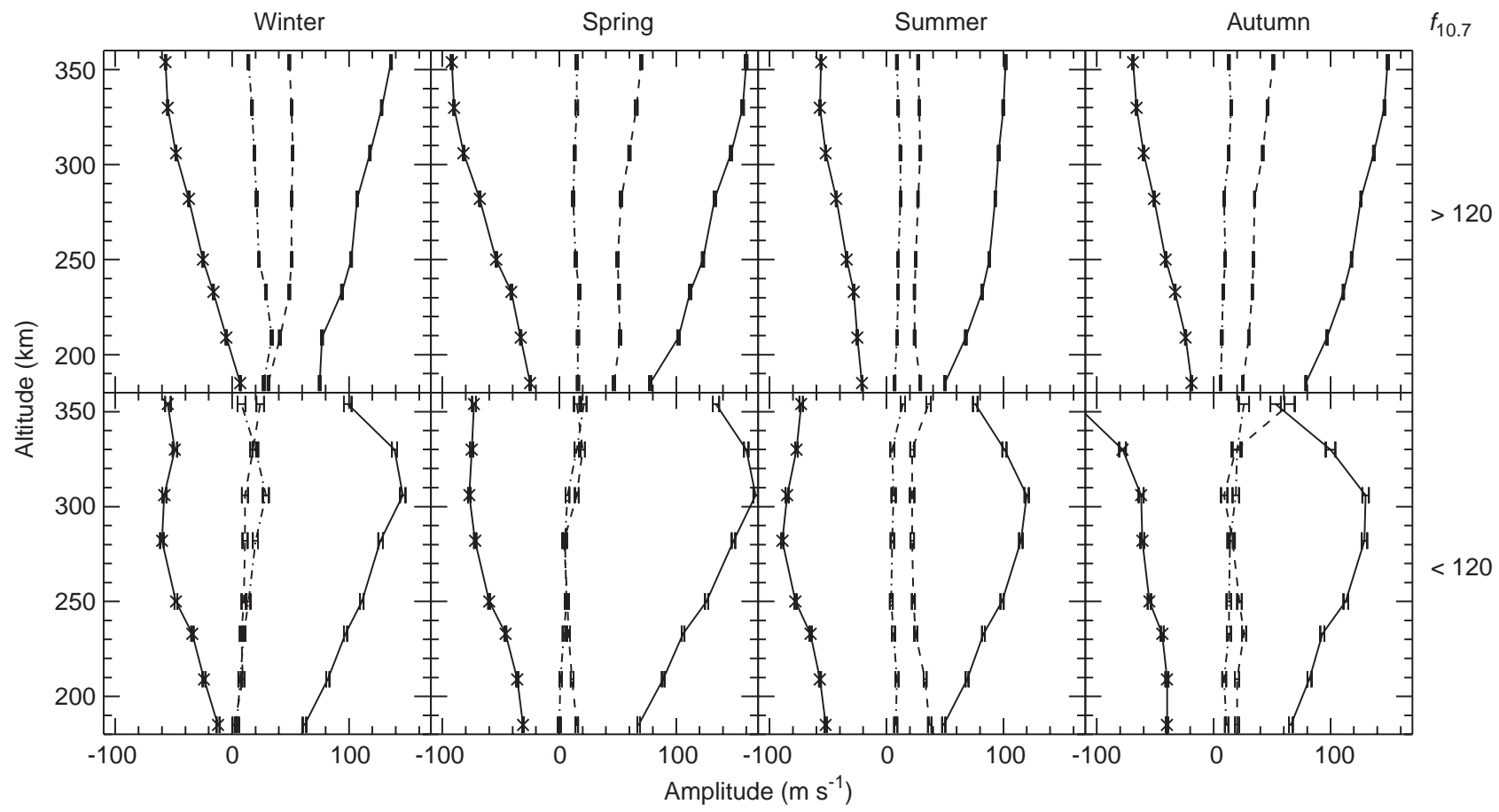

Fig. 5. Height amplitude profiles: mean wind (solid line plus crosses), $A_{24}$ (solid line), $A_{12}$ (dashed line), and $A_{8}$ (dash-dotted line). Errorbars are included

Hedin et al. (1991) (HWM) published an empirical model of thermospheric winds using data from satellite and ground-based measurements. Here comparisons are made between both models at $250 \mathrm{~km}$ height, and for the same geophysical conditions (see Fig. 7). Very good agreement has been found around midnight, except in the summer and high solar flux case, and the autumn and low solar flux case, where the difference can reach around $50 \mathrm{~m} \cdot \mathrm{s}^{-1}$. For solar maximum periods, a relatively good agreement has been found between 15 and 5 UT, except in summer in the morning and in winter between 16 an 22 UT. During the daytime HWM

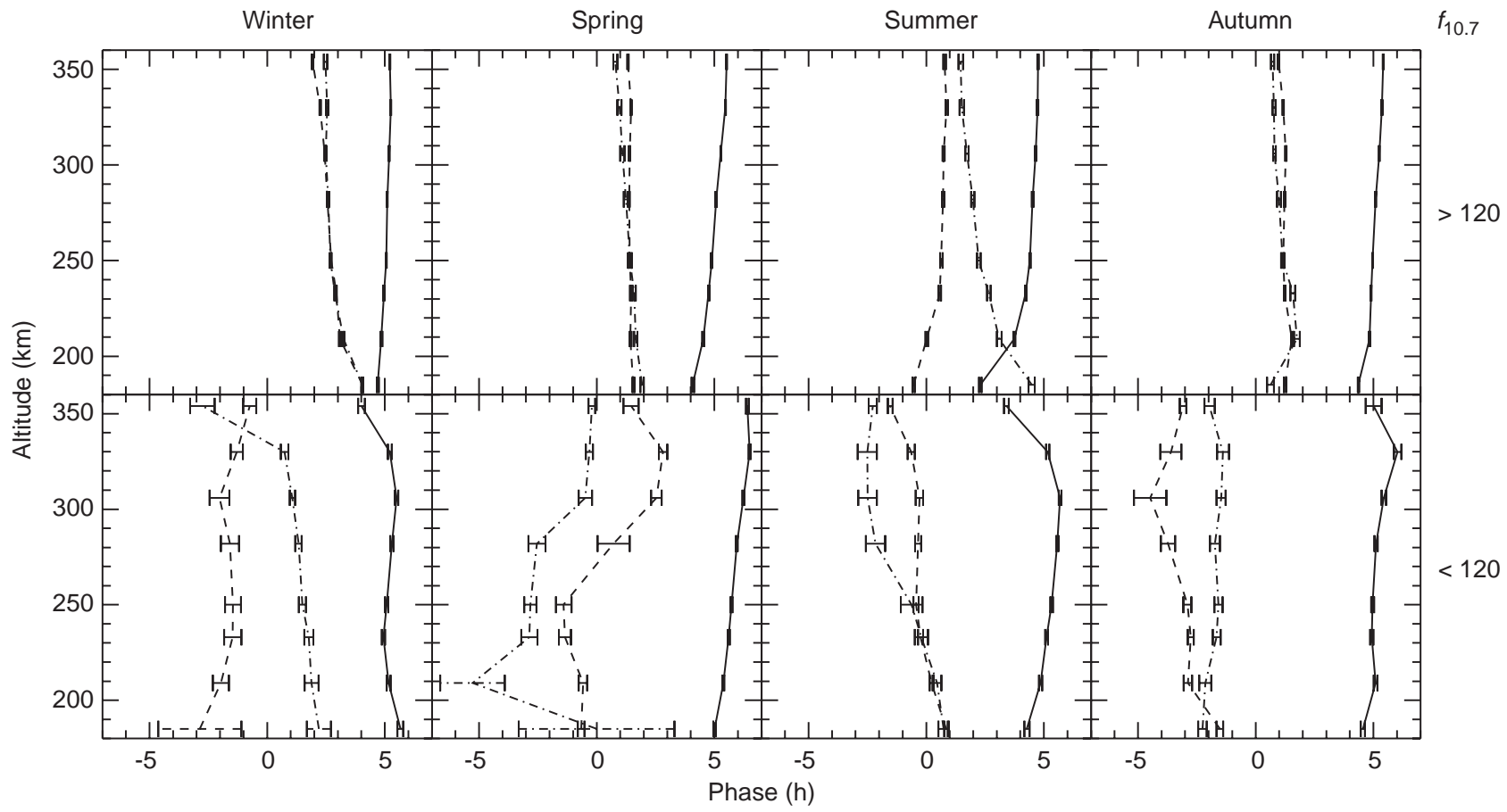

Fig. 6. Height phases profiles: $\phi_{24}$ (solid line), $\phi_{12}$ (dashed line), and $\phi_{8}$ (dash-dotted line). Errorbars are included 


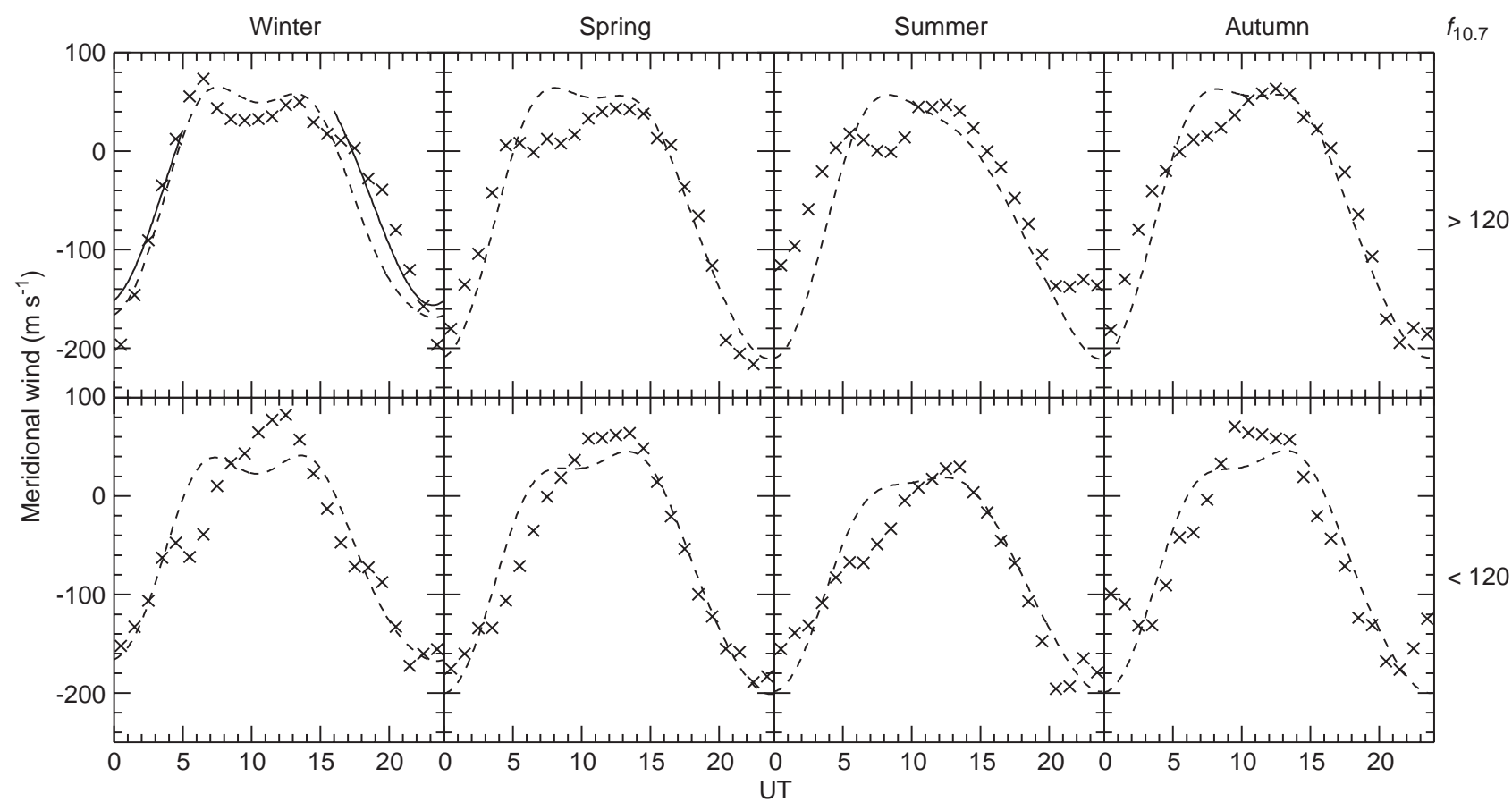

Fig. 7. Comparisons between the present work around $250 \mathrm{~km}$ height (the mean wind is represented by crosses), the HWM model (dashed line) for the same geophysical conditions and the FTH model (solid line) in winter and during high solar activity period

generally overestimates the poleward wind (around 30 $\mathrm{m} \cdot \mathrm{s}^{-1}$ in summer at $8 \mathrm{UT}$ ). For solar minimum periods, larger discrepancies appear: the HWM model overestimates the wind before and ISUT and underestimates it (around $60 \mathrm{~m} \cdot \mathrm{s}^{-1}$ in winter at $12 \mathrm{UT}$ ).

We also compared both models for our lower altitude (see Fig. 8). For high solar activity periods a better agreement has been found during the daytime in fall.
Large differences appear in winter and summer. The nighttime wind is correctly represented except in summer. For low solar activity periods, the agreement between both models is generally better than at $250 \mathrm{~km}$ height, even if some discrepancies appear, especially in summer during the daytime. The differences could be explained because the weakness of the HWM model is a lack of data from high-latitude facilities.

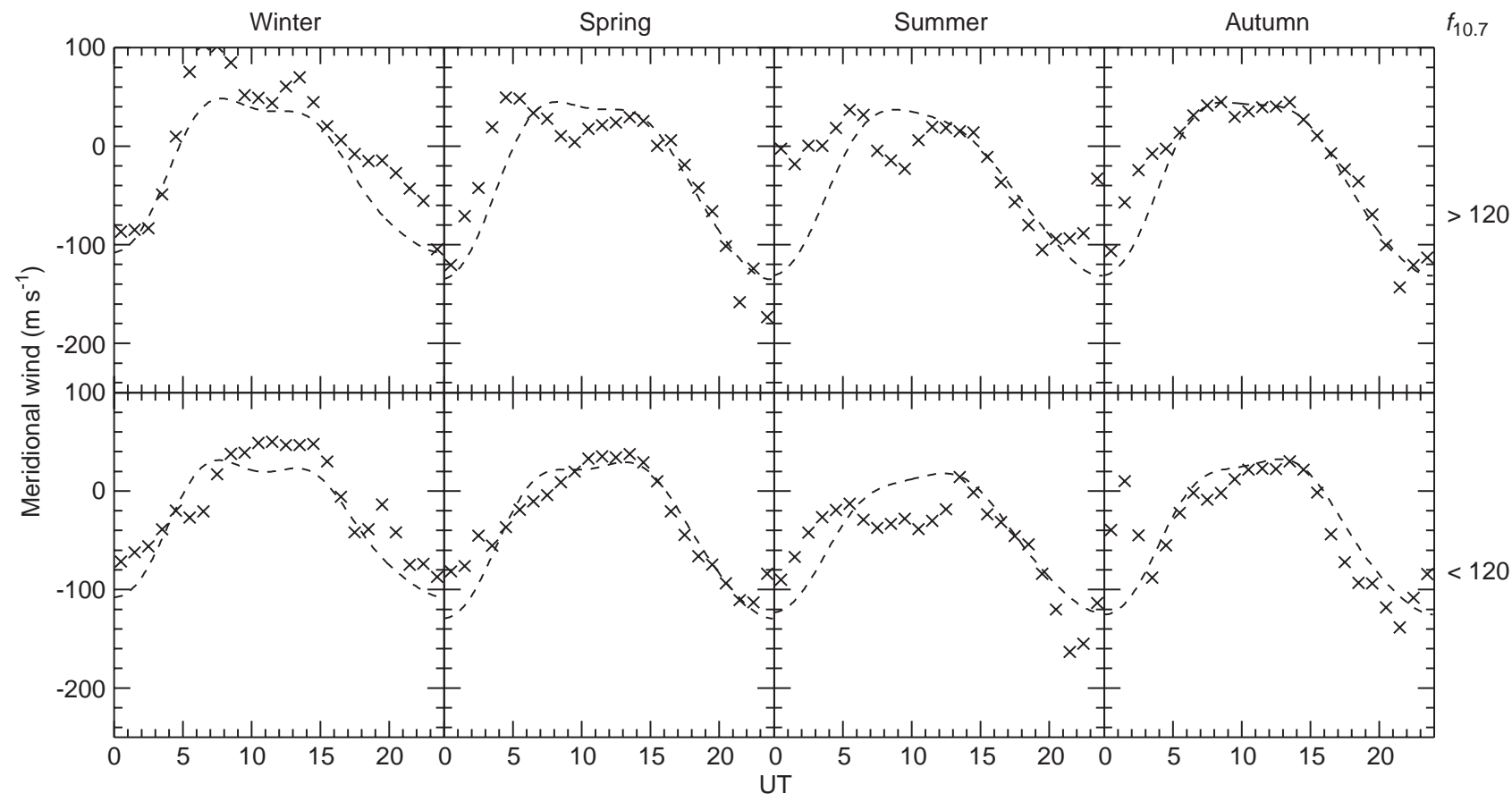

Fig. 8. Comparisons between the mean wind (crosses) at $185 \mathrm{~km}$ height and the HWM model (dashed line) 
It is also worthwhile to compare our results with the recent study of the high-latitude thermospheric neutral wind deduced from a Fabry-Perot interferometer (FPI) over a full solar cycle (Aruliah et al., 1996). The authors showed that the March equinox nighttime winds are larger than the September equinox winds during high and low solar activities. This asymmetry is greater for high solar flux. We have found the same trend regarding the wind around midnight, even if our wind values are larger. Aruliah et al. have found that midnight winds can reach around $-180 \mathrm{~m} \cdot \mathrm{s}^{-1}$ for high solar activity in March, $-100 \mathrm{~m} \cdot \mathrm{s}^{-1}$ in December and in September. For the same conditions, we have found maxima of $-223,-196$, and $-183 \mathrm{~m} \cdot \mathrm{s}^{-1}$. Both studies give the same results regarding the afternoon reversal time: between 15 and 17 UT for us and 17 UT for Aruliah et al. A good agreement is found as well for the morning reversal time during high solar flux periods: between 4 and 6 UT. In contrast these authors did not find any dependence of this time with the solar flux, but the main disagreement between both studies is the amplitude of the equatorward nighttime winds, which can be almost a factor two larger in our study. The weaknesses of FPI measurements have been extensively discussed in Aruliah et al. (1996), and we have already outline in Sect. 2 the small uncertainties of our method. We just note here again that our midnight winds are in very good agreement with the HWM90 model at 250 and $185 \mathrm{~km}$ altitude, and that the wind gradient is quite large in this altitude region.

\section{Conclusion}

The meridional thermospheric neutral wind above Tromsø has been calculated from EISCAT data covering a full solar cycle. The wind is derived using the method described in Lilensten and Lathuillere (1995). From this data base we developed a high-latitude model that depends on UT, four seasons, two solar activity levels, and eight altitudes. Locally disturbed periods are not taken into account. The wind is represented by one mean and three harmonic components with periods of 24,12 , and $8 \mathrm{~h}$.

The main characteristics in wind patterns, northward by day and southward by night, have been noted in previous studies. The mean winds are generally equatorward. Both equinoxes differ, especially the nighttime maximum equatorward value. The summer season drastically differs from the other ones, especially the mean wind and the nighttime maximum equatorward value. The mean wind and the semidiurnal amplitude show an $f_{10.7}$ dependence. The most interesting wind feature is the behavior of the reversal time in the morning with the solar activity.

Comparisons with the FTH model give relatively good agreement, as does the Horizontal Wind Model around $250 \mathrm{~km}$. The agreement is even better at the lowest altitude of $185 \mathrm{~km}$. Including our data base in the HWM model may improve its performance. Comparisons with Aruliah's work showed similarities concerning the trends during both equinoxes but large discrepancies in midnight winds.

The meridional wind behavior as a function of altitude has been analyzed. Interesting features appeared, especially the shape of the diurnal component. Phases appear relatively constant with the height. Further investigations are needed to understand these behaviors.

This work is to be included in the international effort to model thermospheric winds at all latitudes. It would be interesting to compare it with results from the new ESR radar located at higher latitude and also from theoretical works, like the thermosphere ionosphere global circulation model (TIGCM) (Roble et al.,1988), or the coupled thermosphere ionosphere model (CTIM) (Fuller-Rowell et al.,1987).

Acknowledgements. The authors are grateful to G. Thuiller, A.E. Hedin, and W. Kofman for helpful discussions.

EISCAT is an international association supported by the research councils of Finland (SA), France (CNRS), the Federal Republic of Germany (MPG), Norway (NAVF), Sweden (NFR), the United Kingdom (SERC), and Japan.

All the computations have been carried out at the Centre de Calcul Intensif de l'Observatoire de Grenoble.

Topical Editor D. Alcayde thanks D. Drob and R. Fujii for their help in evaluating this paper.

\section{References}

Aruliah, A. L., A. D. Farmer, D. Rees, and U. Brandstrom, The seasonal behavior of high-latitude thermospheric winds and ion velocities observed over one solar cycle, J. Geophys. Res., 101, 15701-15711, 1996.

Banks, P. M., and G. Kockarts, Aeronomy, Academic Press, New York, 1973.

Buonsanto, M. J., Neutral winds in the thermosphere at midlatitudes over a full solar cycle: a tidal decomposition, $J$. Geophys. Res., 96, 3711-3724, 1991.

Duboin, M.-L., and M. Lafeuille, Thermospheric dynamics above Saint-Santin: statistical study of the data set, J. Geophys. Res., 97, 8661-8671, 1992.

Fauliot, V., G. Thuiller, and M. Herse, Observation of the F-region horizontal and vertical winds in the auroral zone, Ann. Geophysicae, 11, 17-28, 1993.

Fuller-Rowell, T. J., D. Rees, S. Quegan, R. J., Moffett, and G. J. Bailey, Interactions between thermospheric composition and the polar thermosphere using a coupled global model, $J$. Geophys. Res., 92, 7744-7748, 1987.

Hagan, M. E., Quiet-time upper thermospheric winds over Millstone Hill between 1984 and 1990, J. Geophys. Res., 98, 3731-3739, 1993.

Hedin, A. E., et al., Revised global model of thermosphere winds using satellite and ground-based observations, J. Geophys. Res., 96, 7657-7688, 1991 .

Hedin, A. E., M. J. Buonsanto, M. Codrescu, M.-L. Duboin, C. G. Fesen, M. E. Hagan, K. L. Miller, and D. P. Sipler, Solar activity variations in mid-latitude thermospheric meridional winds, $J$. Geophys. Res., 99, 17601-17608, 1994.

Hedin, A. E., Extension of the MSIS thermosphere into the middle and lower atmosphere, J. Geophys. Res., 96, 1159-1172, 1991.

IAGA Working Group, IGRF 1995: revision, EOS, AGU 77, 153, 1996.

Lathuillere, C., J. Lilensten, B. Gault, and G. Thuiller, The meridional wind in the auroral thermosphere: results from EISCAT and WINDII- $O^{1} D$ coordinated measurements, $J$. Geophys. Res., 102, 4487-4492, 1997. 
Lilensten, J., and C., Lathuillere, The meridional thermospheric neutral wind measured by the EISCAT radar, J. Geomagn. Geoelectr., 47, 911-920, 1995.

Lilensten, J., G. Thuiller, C. Lathuillere, W. Kofman, V. Fauliot, and M. Herse, EISCAT-MICADO coordinated measurements of meridional wind, Ann. Geophysicae, 10, 603-618, 1992.

Lilensten, J., P. L. Blelly, W. Kofman, D. Alcaydé, Auroral ionospheric conductivities: a comparison between experiment and modeling, and theoretical $f_{10.7}$-dependent model for EISCAT and ESR, Ann. Geophysicae, 14, 1297-1304, 1996.

Oliver, W. L., S. Fukao, T. Takami, M. Yamamoto, T. Tsuda, T. Nakamura, and S. Kato, Thermospheric meridional winds measured by the middle and upper atmosphere radar, $J$. Geophys. Res., 95, 7683-7692, 1990.

Rees, D., R. W. Smith, P. J. Charleton, F. G. McCormac, N. Lloyd, and A. Steen, The generation of vertical thermospheric winds and gravity waves at auroral latitudes. I. Observation of vertical winds, Planet. Space Sci., 32, 667-684, 1984.

Roble, R. G., E. C. Ridley, A. D. Richmond, and R. E. Dickinson, A coupled thermosphere/ionosphere general circulation model, Geophys. Res. Lett., 15, 1325-1328, 1988.
Salah, J. E., Interim standard for the ion-neutral atomic oxygen collision frequency, Geophys. Res. Lett., 20, 1543-1546, 1993.

Salah, J. E., and J. M. Holt, Mid-latitude thermospheric winds from incoherent-scatter radar and theory, Radio Sci., 9, 301313, 1974.

Schunk, R. W., and A. F. Nagy, Electron temperature in the Fregion of the ionsphere: theory and observation, Rev. Geophys. Space Phys., 16, 355-399, 1978.

Titheridge, J. E., The meridional winds in the ionosphere at $70 \mathrm{~N}$, Planet. Space Sci., 39, 657-669, 1991.

Vasseur, G., Vents dans la thermosphere deduit des mesures par diffusion de Thomson, Ann. Geophys., 25, 517-524, 1969.

Winser, K. J., A. D. Farmer, D. Rees, and A. Aruliah, Ionneutral dynamics in the high-latitude ionosphere: first results from the INDI experiment, J. Atmos. Terr. Phys., 50, 369-377, 1988. 